\title{
Editorial:
}

\section{Canadian Association on Gerontology Policy Statement on Home Care in Canada}

Statement of the Problem: Canada does not have a universally accessible, comprehensive home care policy or program.

Scope: Home care is not currently available to Canadians on a universal basis; it falls outside of the realm of Medicare. Provinces vary in the services they offer, eligibility criteria, and the extent of and whether user fees are charged. Yet, for many, home care is considered a necessary part of an appropriate and integrated health care system. The National Forum on Health (1997), the National Advisory Council on Aging (1995), the Canadian Home Care Association (1996) and the Victoria Order of Nurses of Canada (1997) have all recommended comprehensive community based health and support services be recognized as essential services in the Canadian health care system.

Indeed, the vision of health reform in the 1990 s in virtually all provinces (Mhatre \& Deber, 1992) recognizes home care as a cornerstone of a comprehensive, appropriate health care system for seniors and for individuals of all ages.

Analysis of the Evidence: Proponents of expanded home care services argue that these services are both appropriate and cost effective. The cost effectiveness research has been far from conclusive on this issue. Many of the early research studies out of the United States (see Chappell, 1994 for review) find that home care services are not necessarily cost effective, although recipients report higher quality of life. One of the difficulties is that this research tends not to distinguish between different functions of home care: as a substitution for acute care hospitalization; as a substitution for long-term institutional care; and for maintenance and prevention. Some studies have concluded that home care is cost effective if it is targetted only to those individuals who would have been institutionalized. Weissert (1985), a well-known proponent of the position that home care is not less expensive than long-term institutional care, recently argued that it can be (Weissert et al., 1997). Only at the current time is research examining this issue in a more sophisticated fashion. This is particularly true with Health Canada's establishment of the Health Transition Fund. A recent report from Saskatchewan (HSURC, 1998) concludes home care can substitute 
for acute care hospital utilization; that adult medical and surgical patients can be provided with alternate care, mostly home care, to achieve the same health outcomes at less cost. For home care to serve this purpose, individuals must be discharged in a timely fashion from the hospital. There seems to be little argument that home care services can be cost effective, the question to be answered is, under what circumstances and at what level of need. The issue of quality of life and appropriateness of care receives little dispute - individuals prefer to be in familiar surroundings in their own homes when they are ill.

The facts also suggest that home care is underfunded. In 1997-1998, just over 2 million dollars were spent in Canada on public home care expenditures (Health Canada, 1998); this was only 4 per cent of total public health care spending. Furthermore, it is estimated that approximately 90 per cent of home care services are publicly funded (Sorochan, 1995). While home care budgets across the country are increasing, the additional funds are insufficient to offset increased demand for intense post acute care, resulting from health care restructuring and earlier discharge from acute care hospitals. Long term chronic care through community care is not only threatened but is being decreased (Home Support Administrators of Greater Victoria and the Islands, 1998). In other words, there are real reasons to be concerned about under-funding of home care in Canada.

Finally, we know that between 70 and 80 per cent of personal care provided to seniors comes from informal networks of family and friends (Kane \& Kane, 1985). With health care restructuring, including the closure of hospital beds and, in some places, entire hospitals, earlier discharges from hospitals, increased out-patient surgeries, and a restriction on building more long-term care beds without comparable increases in home care funding, there is an increased burden on informal caregivers. It is questionable whether caregivers can provide any more care than they are already; and at considerable costs to themselves (RIS MRC CFAS, 1998). We know that the lack of an informal caregiver is the greatest predictor of long-term institutional care among the elderly (Shapiro \& Tate, 1988) and that the receipt of home care can prolong informal caregiving and prevent burn-out (Horowitz \& Dobrof, 1982; Chappell, 1992).

Recommendation: The Canadian Association on Gerontology recommends that the federal, provincial, and territorial governments move without delay to ensure a universally accessible, comprehensive home care program for Canadians.

The program must have:

a) adequate funding for training, service delivery and evaluation;

b) national standards for training, service delivery and evaluation;

c) appropriate services available for informal caregivers. 


\section{References}

Chappell, N.L. (1992). Social support and aging. Butterworths Canada Ltd.

Chappell, N.L. (1994). Home care research: What does it tell us? The Gerontologist, 34(1), 116-120.

Health Canada. (1998). Public home care expenditures in Canada 1975-76 to 1997-98. Fact Sheets.

Health Services Utilization and Research Commission (HSURC). (1998 March). Hospital and home care study.

Home Support Administrators of Greater Victoria and the Islands. (1998 May). Home support services in capital health region: A utilization study, 1989-1998.

Horowitz, A., \& Dobrof, R. (1982). The role of families in providing long-term care to the frail and chronically ill elderly living in the community. Health Care Financing Administration, USDHHS Grant No. 18-P-97541/2-02.

Kane, R.A., \& Kane, R.L. (1985). Feasibility of universal long-term-care benefits: ideas from Canada. New England Journal of Medicine, 312(21), 1357-1364.

Mhatre, S.L., \& Deber, R.B. (1992). From equal access to health care to equitable access to health: A review of Canadian provincial health commissions and reports. International Journal of Health Services, 22(4), 645-668.

RIS MRC CFAS (Resource implications study of Medical Research Council Cognitive Function and Ageing Study) (1998). Mental and physical frailty in older people: the costs and benefits of informal care. Ageing and Society, 18, 317-354.

Shapiro, E., \& Tate, R. (1988). Who is really at risk of institutionalization? The Gerontologist, 29(2), 237-245.

Sorochan, M. (1995 January). Home care in Canada. Caring Magazine.

Weissert, W.G. (1985). Seven reasons why it is so difficult to make communitybased long term care cost-effective. Health Services Research, 20(4), 423-433.

Weissert, W.G., Lesnick T., Musliner, M., \& Foley, K.A. (1997). Cost savings from home and community-based services: Arizona's capitated Medicaid longterm care program. Journal of Health Politics, Policy \& Law, 22(6). 1329-1357.

This position paper was prepared by Neena L. Chappell, Ph.D., Director of the Centre on Aging, University of Victoria, at the request of the Board of Directors of the Canadian Association on Gerontology. It was approved by the Board as an official policy statement of the CAG in April, 1999. 